\title{
A STUDY OF HAEMOGLOBINOPATHIES AND HAEMOGLOBIN VARIANTS USING HIGH PERFORMANCE LIQUID CHROMATOGRAPHY (HPLC) IN A TEACHING HOSPITAL OF ODISHA
}

\author{
Sarojini Raman', Nageswar Sahu², Urmila Senapati ${ }^{3}$
}

${ }^{1}$ Assistant Professor, Department of Pathology, Kalinga Institute of Medical Sciences (KIMS), KIIT University, Bhubaneswar, Odisha. ${ }^{2}$ Assistant Professor, Department of Pathology, Kalinga Institute of Medical Sciences (KIMS), KIIT University, Bhubaneswar, Odisha. ${ }^{3}$ Professor and HOD, Department of Pathology, Kalinga Institute of Medical Sciences (KIMS), KIIT University, Bhubaneswar, Odisha.

\section{ABSTRACT}

\section{BACKGROUND}

Thalassaemias and haemoglobinopathies are highly prevalent in India. Identification of these disorders is important for epidemiologic purposes and for prevention of thalassaemia major and clinically severe haemoglobinopathies. The use of high performance liquid chromatography (HPLC) as a screening method for detection of these groups of disorder is increasing in last two decades.

The aim is to study of thalassaemias and haemoglobinopathies using high performance liquid chromatography as a diagnostic tool in patients of a tertiary care hospital of Odisha.

\section{METHODS AND MATERIALS}

A total of 788 cases were included in the study. Samples were analysed on the BIO-RAD D-10TM dual mode HPLC system. Personal history, family history, peripheral blood findings and sickling test result were correlated. Family studies were done whenever required and possible. However, secondary confirmatory tests were not done. Statistical analysis was done on Microsoft Excel. Continuous variables were expressed as mean \pm SD. Categorical variables were expressed as frequencies and percentages.

\section{RESULTS}

Abnormal HPLC patterns were seen in $37.18 \%$ of cases. Sickle cell heterozygous (15.10\%), sickle cell homozygous (9.90\%) and $\beta$ thalassaemia trait $(6.10 \%)$ were the most common abnormalities found. Other patterns detected include $\beta$-thalassaemia major and intermedia, compound heterozygous state of $\mathrm{HbS}$ and $\beta$-thalassaemia, $\mathrm{HbE}$ trait, $\mathrm{HbE}$ disease, double heterozygous state of $\mathrm{HbS}$ and $\mathrm{HbE}, \mathrm{HbE}$ and $\beta$-thalassaemia and $\mathrm{HbS}$ and hereditary persistent of foetal haemoglobin, HbD Punjab trait, Hb Lepore trait and $\mathrm{HbH}$ disease.

\section{CONCLUSION}

Sickle cell along with $\beta$-thalassaemias are the major abnormal haemoglobins in Odisha. Premarital and antenatal screenings are important measures to prevent birth of children with severe haemoglobin disorders. HPLC is a rapid and reliable technique for identification of various haemoglobin fractions.

\section{KEYWORDS}

Haemoglobinopathies, Haemoglobin Variants, High Performance Liquid Chromatography, Prevalence.

HOW TO CITE THIS ARTICLE: Raman S, Sahu N, Senapati U. A study of haemoglobinopathies and haemoglobin variants using high performance liquid chromatography (HPLC) in a teaching hospital of Odisha. J. Evolution Med. Dent. Sci. 2017;6(11):842-849, DOI: $10.14260 /$ Jemds/2017/183

\section{BACKGROUND \\ Haemoglobinopathies and thalassaemias are the most common single gene disorders in the world.[1] The prevalence of thalassaemias and haemoglobinopathies varies with geographic locations.[2] World Health Organization figures estimate that $5 \%$ of the world population are carriers of a potentially pathological haemoglobin gene.[3] The general incidence of thalassaemia trait and sickle cell haemoglobinopathy in India varies between 3-17\% and 1- $44 \%$ respectively.}

Financial or Other, Competing Interest: None.

Submission 27-12-2016, Peer Review 21-01-2017,

Acceptance 27-01-2017, Published 06-02-2017.

Corresponding Author:

Dr. Nageswar Sahu,

Assistant Professor,

Department of Pathology,

KIMS \& PBMH, KIIT University,

Patia, Bhubaneswar-751024, Odisha.

E-mail: nageswar.sahu@yahoo.in

DOI: $10.14260 /$ jemds $/ 2017 / 183$

\section{(c) $(1)$}

But because of consanguinity and caste and area endogamy, some communities show a very high incidence, making this group of diseases a major public health problem in our country.[4,5,6]

Diagnosis of haemoglobinopathies in most centres in India relies upon conventional methods like, clinical and family history, haemoglobin concentration, red cell indices, $\mathrm{HbA}_{2}$, $\mathrm{HbF}$ estimation, sickling test, and $\mathrm{Hb}$ electrophoresis. Various limitations of these methods have been felt in recent years. One of the most important is the difficulty in the identification of $\mathrm{Hb}$ variants with same electrophoretic mobility, such as in $A_{2} / E / C / O-A r a b$ and $S / D / G / Q / L e p o r e$. Other issues come up in diagnosis of $\mathrm{HbS}$ traits where low quantity of $\mathrm{HbS}$ is associated with negative sickling test and while diagnosing certain compound heterozygous states such as, for $\mathrm{HbD}$ and $\mathrm{HbE}, \mathrm{HbS}$ and $\beta$-thalassaemia, $\mathrm{HbS}$ and HbD. ${ }^{[7,8]}$

High performance liquid chromatography (HPLC) being an automated instrument is highly sensitive and specific, has high resolution and helps in quantification of various haemoglobins. 
It acts as a good alternative to electrophoresis.[9,10] With the help of basic haematological parameters like $\mathrm{Hb} \%$ and RBC indices along with HPLC, a laboratory can identify around $75 \%$ of the common variants encountered, without the need for confirmatory studies such as alkaline and acid electrophoresis.[11]

The knowledge of the common $\mathrm{Hb}$ variants encountered in a particular area is important for the formulation of specific diagnostic, preventive and therapeutic strategies. As the exact data pertaining to the prevalence of haemoglobinopathies in this region is scarce, we considered it important to find out the extent of burden of the common $\mathrm{Hb}$ disorders in patients of a tertiary care hospital of Odisha.

\section{MATERIALS AND METHODS}

This was a prospective study conducted over a period of 2 years. All the cases received in our laboratory for haemoglobin HPLC were considered which included patients opting for premarital or antenatal haemoglobin analysis, patients having positive family history and cases suspected of haemoglobinopathy on the basis of red cell indices. However, patients with a history of blood transfusion within the last 1 month and infants with inconclusive HPLC findings were excluded. A total of 788 cases were included in the study. The geographical distribution included whole Odisha, along with cases from West Bengal, Chhattisgarh and Jharkhand.

A detailed clinical history, family history and history of blood transfusion were obtained from each patient. Blood samples were collected in vacutainer tubes containing dipotassium EDTA and analysed in Beckman Coulter (LH750) automated cell counter for complete blood count. For each patient, a peripheral blood smear (PBS) was prepared and stained with Leishman stain. Keeping in mind that $\mathrm{HbS}$ prevalence is high in Odisha[4,12] sickling test (Using sodium meta-bisulphite) was done in all the samples.

HPLC was performed on BIO-RAD D-10TM dual mode instrument manufactured by Bio-Rad laboratories, which utilizes the principle of cation-exchange high performance liquid chromatography (CE-HPLC). Before every run, the instrument was calibrated with the help of $\mathrm{D}-10^{\mathrm{TM}}$ $\mathrm{HbA}_{2} / \mathrm{F} / \mathrm{A}_{1 \mathrm{C}}$ calibrator and two levels of controls. The sample were injected into the analysis stream and separated by cation exchange cartridge using a phosphate ion gradient generated by mixing two buffers of different ionic strengths to elute the different haemoglobins. The separated haemoglobin fractions pass through a flow cell, where absorbance is measured at $415 \mathrm{~nm}$ with simultaneous use of secondary wavelength of $690 \mathrm{~nm}$ to reduce background noise. A printed chromatogram is delivered by the software, where the different peaks are identified in different windows with relevant information like retention time, relative percentage and area. The total area acceptable was between one to four million. Haemoglobins were identified on the basis of retention time. Quantification of the haemoglobin was done by determining the area under the corresponding peak in the elution profile. If a peak eluted at a retention time that is not predefined, it was labelled as unknown. In these cases the identification of $\mathrm{Hb}$ variant was done by manufacturer assigned retention time in the manual.

Diagnosis was made by seeing the chromatogram finding in correlation with age, $\mathrm{Hb} \%, \mathrm{RBC}$ indices, PBS findings and the result of sickling test. The presence of $\mathrm{HbH}$ was confirmed by using brilliant cresyl blue test for $\mathrm{HbH}$ inclusions. A second confirmatory method like $\mathrm{Hb}$ electrophoresis at alkaline $\mathrm{pH}$, isoelectric focusing and molecular studies were not done though recommended to many patients.

\section{Statistics}

Statistical analysis was done on Microsoft Excel. Continuous variables were expressed as mean $\pm \mathrm{SD}$. Categorical variables were expressed as frequencies and percentages.

\section{RESULTS}

Out of 788 cases 495 (62.82\%) were normal and $293(37.18 \%)$ cases showed abnormal haemoglobin fractions. Male to female ratio in the abnormal group was 4:3. Age group ranged from 6 months to 84 years with a mean of 19.18 years and median of 17 years. Normal chromatogram showed primarily $\mathrm{HbA}$, a small percentage of $\mathrm{A}_{2}(<3.9 \%)$ and traces of HbF. P2 and P3 are normal associates of HbA. Table$1 \& 2$ shows the number, age group affected, $\mathrm{Hb} \%$, RBC indices and chromatogram finding of all abnormal cases.

\begin{tabular}{|c|c|c|c|c|c|c|c|c|c|c|}
\hline \multirow{2}{*}{ Diagnosis } & \multirow{2}{*}{\begin{tabular}{|c|} 
No. of \\
Cases (\%)
\end{tabular}} & \multicolumn{3}{|c|}{ Age (Years) } & \multirow{2}{*}{$\begin{array}{l}\mathrm{Hb}(\mathrm{g} / \mathrm{dL}) \\
\text { Mean } \pm S D\end{array}$} & \multirow{2}{*}{$\begin{array}{c}\text { TRBC }\left(10^{6} / \mu \mathrm{L}\right) \\
\text { Mean } \pm \text { SD }\end{array}$} & \multirow{2}{*}{$\begin{array}{c}\text { MCV(fl) } \\
\text { Mean } \pm \text { SD }\end{array}$} & \multirow{2}{*}{$\begin{array}{l}\text { MCH (pg) } \\
\text { Mean } \pm \text { SD }\end{array}$} & \multirow{2}{*}{$\begin{array}{c}\text { MCHC }(\mathrm{g} / \mathrm{dL}) \\
\text { Mean } \pm \text { SD }\end{array}$} & \multirow{2}{*}{$\begin{array}{c}\text { RDW-CV(\%) } \\
\text { Mean } \pm \text { SD }\end{array}$} \\
\hline & & Range & Mean & Median & & & & & & \\
\hline$\overline{\mathrm{AS}}$ & $119(15.1)$ & $0.5-84$ & 19.61 & 15 & $10.14 \pm 2.59$ & $4.31 \pm 1.14$ & $76.87 \pm 10.56$ & $23.86 \pm 3.85$ & $30.94 \pm 1.39$ & $18.14 \pm 5.55$ \\
\hline SS & $78(9.90)$ & $0.7-48$ & 15.32 & 12.5 & $7.81 \pm 1.89$ & $3.02 \pm 0.87$ & $84.14 \pm 12.00$ & $26.50 \pm 4.43$ & $31.46 \pm 3.04$ & $20.44 \pm 3.57$ \\
\hline BTT & $48(6.10)$ & $2-64$ & 28.22 & 27 & $10.19 \pm 2.00$ & $5.12 \pm 1.11$ & $66.23 \pm 5.69$ & $19.74 \pm 1.85$ & $29.85 \pm 1.00$ & $17.98 \pm 2.72$ \\
\hline BTI & $01(0.12)$ & \multicolumn{3}{|c|}{7} & 5.8 & 2.88 & 83.6 & 24.6 & 29.4 & 41.9 \\
\hline BTM & $07(0.89)$ & $0.6-1$ & 0.7 & 0.6 & $5.2 \pm 0.9$ & $2.04 \pm 0.36$ & $74.36 \pm 5.46$ & $25.71 \pm 3.2$ & $33.28 \pm 2.99$ & $32.31 \pm 3.96$ \\
\hline$S \beta$ & $22(2.79)$ & $1-46$ & $\mid 17.77$ & 12.5 & $7.11 \pm 2.11$ & $3.28 \pm 0.92$ & $73.30 \pm 7.38$ & $22.23 \pm 2.54$ & $30.31 \pm 0.73$ & $22.84 \pm 4.13$ \\
\hline $\overrightarrow{\mathrm{AE}}$ & $06(0.76)$ & $1-21$ & 10.66 & 11.5 & $9.76 \pm 3.03$ & $4.52 \pm 1.28$ & $71.25 \pm 9.81$ & $21.55 \pm 2.95$ & $30.27 \pm 0.46$ & $17.98 \pm 5.75$ \\
\hline $\mathrm{EE}$ & $01(0.12)$ & \multicolumn{3}{|c|}{16} & 11.8 & 5.73 & 64.7 & 20.6 & 31.9 & 15.9 \\
\hline $\mathrm{E} \beta$ & $05(0.63)$ & $1-53$ & 13.8 & 5 & $5.35 \pm 0.9$ & $2.50 \pm 0.56$ & $66.96 \pm 8.07$ & $20.18 \pm 2.95$ & $30.11 \pm 0.98$ & $29.45 \pm 6.13$ \\
\hline SE & $01(0.12)$ & \multicolumn{3}{|c|}{27} & 10.3 & 3.07 & 69.2 & 23.4 & 33.8 & 14.2 \\
\hline SF & $02(0.25)$ & \multicolumn{3}{|c|}{28,40} & $9.2,9.9$ & $3.3,3.4$ & $84.2,91.7$ & $27.9,28.8$ & $31.4,33.1$ & $14.4,19.5$ \\
\hline $\mathrm{AD}$ & $01(0.12)$ & \multicolumn{3}{|c|}{24} & 9.9 & 4.3 & 92.2 & 32.4 & 33.8 & 16.8 \\
\hline $\mathrm{HbH}$ disease & $01(0.12)$ & \multicolumn{3}{|c|}{41} & 6.9 & 3.17 & 78.8 & 21.7 & 27.6 & 24.7 \\
\hline Lepore trait & $01(0.12)$ & \multicolumn{3}{|c|}{24} & 6.3 & 2.09 & 63.8 & 19.1 & 29.9 & 22.1 \\
\hline
\end{tabular}


$\mathrm{Hb}=$ Haemoglobin, $\mathrm{TRBC}=$ Total RBC count, $\mathrm{MCV}=$ Mean corpuscular volume, $\mathrm{MCH}=$ Mean corpuscular haemoglobin, $\mathrm{MCHC}=\mathrm{Mean}$ corpuscular haemoglobin concentration, RDW=Red cell distribution width, SD=Standard deviation

\begin{tabular}{|c|c|c|c|c|c|c|c|c|c|}
\hline \multirow{2}{*}{ Diagnosis } & \multicolumn{2}{|c|}{$A_{0}(\%)$} & \multicolumn{2}{|c|}{$A_{2} / E(\%)$} & \multicolumn{2}{|c|}{ F (\%) } & \multicolumn{2}{|c|}{ S (\%) } & \multirow{2}{*}{$\begin{array}{c}\text { Other (\%) } \\
\text { (RT in } \\
\text { Minutes) }\end{array}$} \\
\hline & Range & Mean \pm SD & Range & Mean \pm SD & Range & Mean \pm SD & Range & Mean \pm SD & \\
\hline AS & $32.5-77.5$ & $59.7 \pm 6.98$ & $1.6-4.9$ & $3.23 \pm 0.63$ & $0.0-18.5$ & $2.43 \pm 3.60$ & $13.2-58.9$ & $26.50 \pm 6.83$ & \\
\hline SS & $2.2-28.4$ & $6.38 \pm 4.17$ & $1.1-4.9$ & $2.77 \pm 0.85$ & $7.9-45.2$ & $22.03 \pm 8.36$ & $37.4-82.3$ & $64.7 \pm 9.41$ & \\
\hline BTT & $75.8-85.8$ & $81.7 \pm 2.17$ & $4.1-8.2$ & $5.03 \pm 0.85$ & $0.0-6.4$ & $1.28 \pm 1.36$ & & & \\
\hline BTI & \multicolumn{2}{|c|}{6.6} & \multicolumn{2}{|c|}{1.8} & \multicolumn{2}{|c|}{81.7} & & & \\
\hline BTM & $1.6-22.6$ & $10.67 \pm 8.11$ & $0.6-3.3$ & $1.95 \pm 0.95$ & $61.8-85.9$ & $76.25 \pm 8.55$ & & & \\
\hline $\mathrm{S} \beta$ & $3.9-24.7$ & $11.06 \pm 5.71$ & $4.5-8.2$ & $5.93 \pm 0.99$ & $3.0-30.0$ & $13.89 \pm 8.20$ & $29.6-81.0$ & $64.86 \pm 11.82$ & \\
\hline $\mathrm{AE}$ & 61.8-73.4 & $66.0 \pm 4.31$ & 20.6-33.4 & $27.1 \pm 4.1$ & $0.0-1.2$ & $0.63 \pm 0.51$ & & & \\
\hline $\mathrm{EE}$ & \multicolumn{2}{|c|}{6.3} & \multicolumn{2}{|c|}{100.1} & \multicolumn{2}{|c|}{5.2} & & & $6.9(3.78)$ \\
\hline $\mathrm{E} \beta$ & $5.0-29.9$ & $15.28 \pm 9.95$ & $39.8-88.0$ & $60.9 \pm 21.3$ & $17.1-37.3$ & $26.26 \pm 9.2$ & & & \\
\hline SE & \multicolumn{2}{|c|}{$\frac{1}{6.3}$} & \multicolumn{2}{|c|}{$\frac{1}{46.3}$} & \multicolumn{2}{|c|}{5.3} & \multicolumn{2}{|c|}{$\frac{1}{50.8}$} & \\
\hline SF & $2.8-5.6$ & $4.2 \pm 1.97$ & $1.4-1.9$ & $1.65 \pm 0.35$ & $26.7-35.2$ & $30.95 \pm 6.01$ & 50.4-61.0 & $55.7 \pm 7.49$ & \\
\hline $\mathrm{AD}$ & \multicolumn{2}{|c|}{52.9} & \multicolumn{2}{|c|}{3.2} & \multicolumn{2}{|c|}{1.0} & & & $33.3(3.88)$ \\
\hline $\mathrm{HbH}$ disease & \multicolumn{2}{|c|}{66.2} & \multicolumn{2}{|c|}{0.8} & \multicolumn{2}{|c|}{0.0} & & & $15.2(0.39)$ \\
\hline Lepore trait & \multicolumn{2}{|c|}{75.9} & \multicolumn{2}{|c|}{17.2} & \multicolumn{2}{|c|}{0.8} & & & \\
\hline
\end{tabular}

AS=Sickle cell heterozygous, SS=Sickle cell homozygous, $\mathrm{BTT}=\beta$-thalassaemia trait, $\mathrm{BTI}=\beta$-thalassaemia intermedia, $\mathrm{BTM}=\beta$-thalassaemia major, $\mathrm{S} \beta=$ Compound heterozygous for $\mathrm{Hb} \mathrm{S}$ and $\beta$-thalassaemia, $\mathrm{AE}=\mathrm{Hb} \mathrm{E}$ heterozygous, $\mathrm{EE}=\mathrm{Hb} \mathrm{E}$ homozygous, $\mathrm{E} \beta=$ Compound heterozygous for $\mathrm{Hb} \mathrm{E}$ and $\beta$ thalassaemia, $\mathrm{SE}=$ Compound heterozygous for $\mathrm{Hb} \mathrm{S}$ and $\mathrm{Hb} \mathrm{E}$, $\mathrm{SF}=$ Compound heterozygous for $\mathrm{Hb} \mathrm{S}$ and hereditary persistent of foetal haemoglobin, $\mathrm{AD}=\mathrm{Hb} \mathrm{D}$ Punjab heterozygous, $\mathrm{RT}=$ Retention time.

In our study, most common abnormal haemoglobin fraction observed was $\mathrm{HbS}$, seen in $222(28.17 \%)$ patients. Sickling test was positive in all of these cases. $\mathrm{Hb}$ concentration in sickle cell heterozygous (AS) group ranged from 2.6-14.86 g/dL. Anaemia $(<11 \mathrm{~g} / \mathrm{dL})$ was seen in 68 (57.14\%) patients. Red cell morphology was mostly normocytic normochromic and microcytic hypochromic. HbF was mostly normal, with $13(10.92 \%)$ patients having a raised $\mathrm{HbF}(>5.0 \%)$. In sickle cell homozygous (SS) group Hb ranged from $2.9-12.1 \mathrm{~g} / \mathrm{dL}$. Only four (5.1\%) patients had $\mathrm{Hb}>11$ $\mathrm{g} / \mathrm{dL}$. Most of the patients had either normocytic normochromic or microcytic hypochromic blood picture with anisopoikilocytosis [Fig-1a].

All patients of compound heterozygous for $\mathrm{HbS}$ and $\beta$ thalassaemia $(\mathrm{S} \beta)$ were anaemic $(\mathrm{Hb}=3.5-10.22 \mathrm{~g} / \mathrm{dL})$. PBS showed moderate to marked anisopoikilocytosis [Fig-1b]. Two adults with mild anaemia were diagnosed to have compound heterozygous for $\mathrm{HbS}$ and hereditary persistent of foetal haemoglobin (SF) [Fig-1c]. Parenteral study of one case confirmed the diagnosis, while the other case parents did not turn around. The single case of compound heterozygous for $\mathrm{HbS}$ and $\mathrm{HbE}$ (SE) had mild anaemia with microcytosis. Both $\mathrm{HbS}$ and $\mathrm{HbE}$ (eluted in $\mathrm{A}_{2}$ window) were around 50\% [Fig1d].

$\mathrm{HbA}_{2}$ levels of $4-9 \%$ are diagnostic of $\beta$-thalassaemia trait (BTT) in an asymptomatic individual with no or mild anaemia. We got this range of increased $\mathrm{HbA}_{2}$ in 55 patients without any other significant abnormality in chromatogram.
Most of them had microcytic hypochromic blood picture. However, 9 patients were suspected to have either megaloblastic or dimorphic anaemia. HPLC was repeated in 7 of them after nutritional supplements. Repeat $\mathrm{HbA}_{2}$ was normal in 5 of them and were included in normal category. Two cases with persistent raised $\mathrm{HbA} 2$ (>4\%) were diagnosed as BTT. Two patients lost to follow up, were excluded from the study. Total 48 patients were diagnosed as BTT [Fig-2a]. 11 (22.91\%) patients had $\mathrm{Hb}<9 \mathrm{~g} \%$.

Seven cases were diagnosed as $\beta$-thalassaemia major (BTM) [Fig-2b]. All presented in their $1^{\text {st }}$ year of life with $\mathrm{Hb}$ level $\leq 6.5$ g\%. PBS showed marked degree of anisopoikilocytosis with raised RDW, hypochromia, target cells, polychromasia and NRBC. HbF levels were high. One patient had similar presentation at the age of 7 years with $81.7 \% \mathrm{HbF}$ was diagnosed as $\beta$-thalassaemia intermedia (BTI) on the basis of clinical data.

$\mathrm{HbE}$ elutes in the $\mathrm{A}_{2}$ window. We got six cases of $\mathrm{HbE}$ heterozygous (AE) [Fig-2c], one case of $\mathrm{HbE}$ homozygous (EE) [Fig-2d] and five cases of compound heterozygous for $\mathrm{HbE}$ and $\beta$-thalassaemia (E $\beta$ ) [Fig-3a]. All except one AE cases had microcytic hypochromic picture. The EE case was advised HPLC based on severe microcytic hypochromic blood picture with normal $\mathrm{Hb}$ level. All E $\beta$ patients were of paediatric age group except one adult case. Hb value was $4.0-6.13 \mathrm{~g} \%$. The PBS showed anisopoikilocytosis with microcytosis, hypochromia and target cells.

One case having mild normocytic normochromic anaemia showed decreased $\mathrm{A}_{0}$ with an unknown peak of $33.3 \%$ at retention time of 3.88 minutes [Fig-3b]. We diagnosed it as HbD Punjab heterozygous (AD) based on the retention time. One adult patient having an unknown peak of $15.2 \%$ in the $1^{\text {st }}$ minute ( $\mathrm{RT}=0.39$ minutes) was diagnosed as $\mathrm{HbH}$ disease [Fig-3c]. Presence of $\mathrm{HbH}$ inclusion on brilliant cresyl blue stain confirmed the diagnosis. Hb Lepore trait constituted one case. $\mathrm{HbA}_{2}$ was raised to $17.2 \%$ with microcytic hypochromic anaemia [Fig-3d]. 

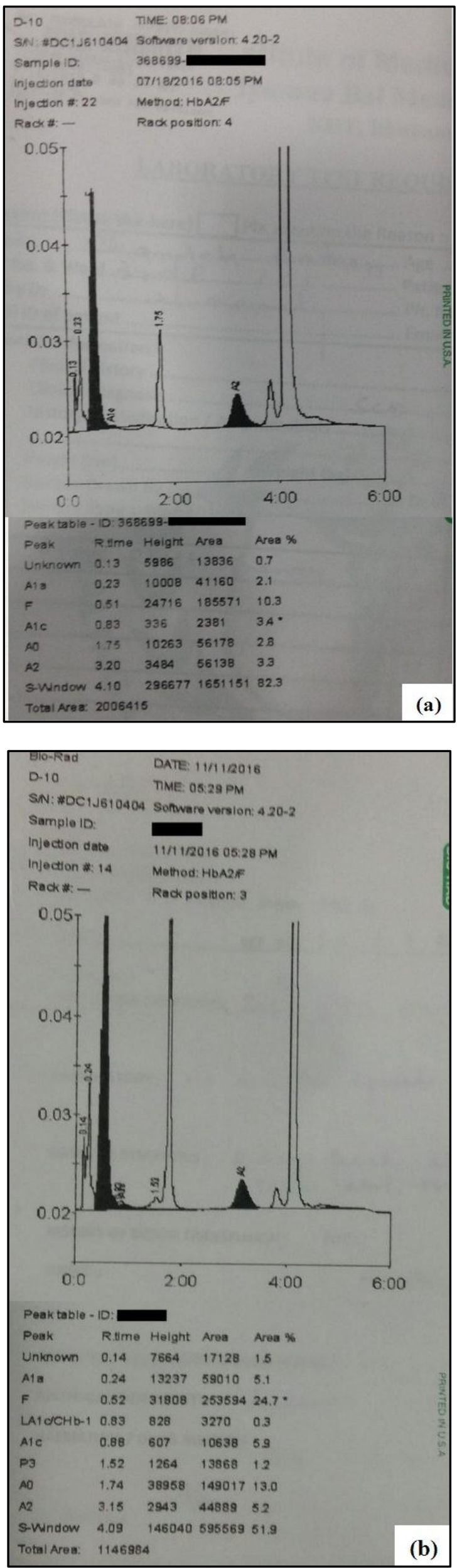
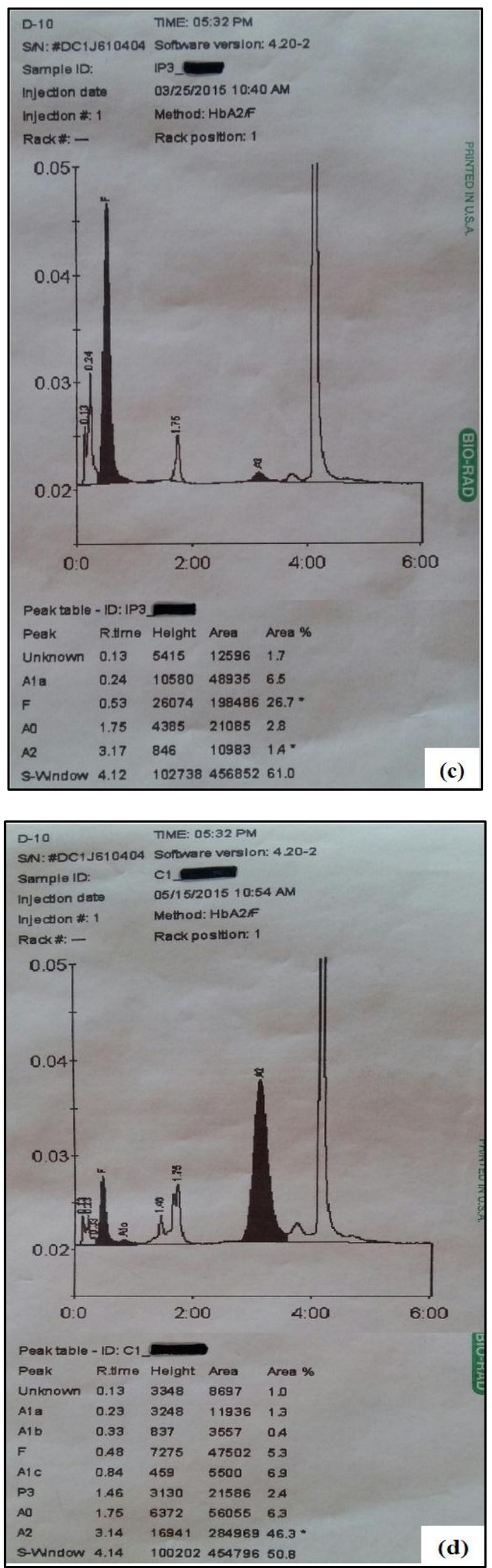

Figure 1. Chromatogram of (a) Sickle Cell Homozygous (SS), (b) Compound Heterozygous for $\mathrm{HbS}$ and $\beta$ -

Thalassaemia ( $S \beta)$, (c) Compound Heterozygous for $\mathrm{HbS}$ and Hereditary Persistent of Foetal Haemoglobin (SF), (d) Compound Heterozygous for $\mathrm{HbS}$ and $\mathrm{HbE}(\mathrm{SE})$ 

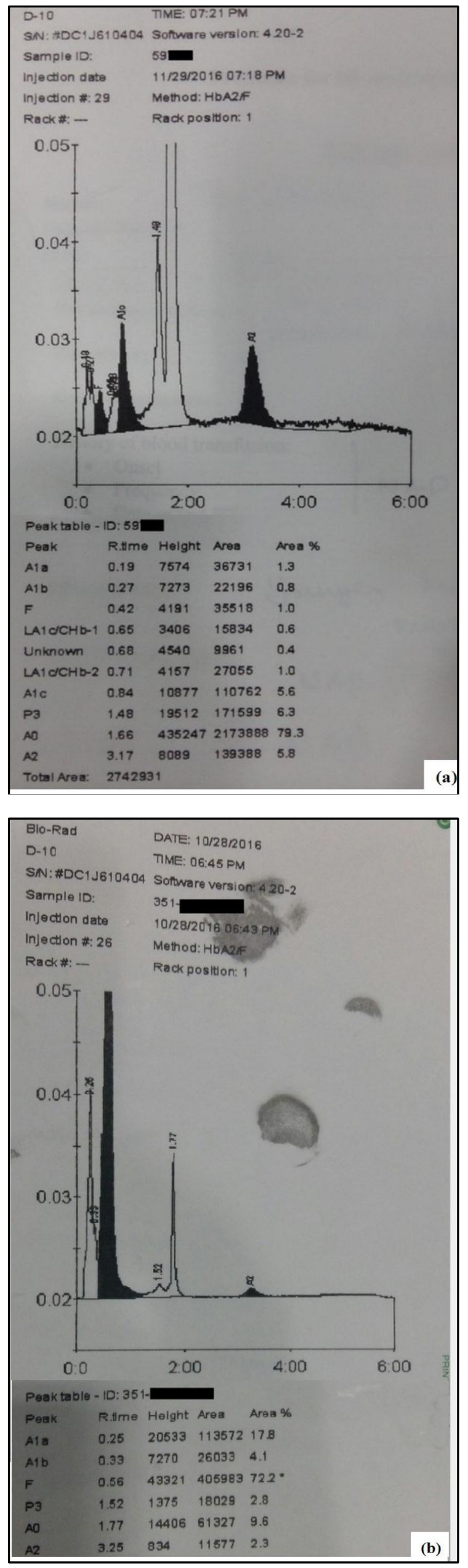
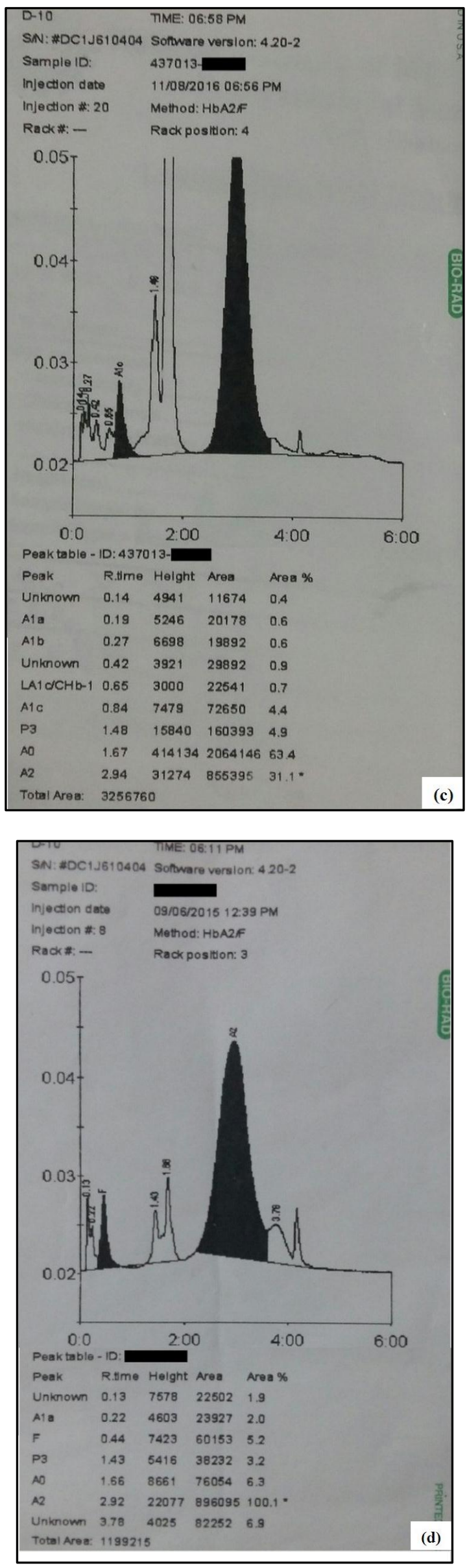

Figure 2. Chromatogram of (a) $\beta$-thalassaemia Trait (BTT), (b) $\beta$-thalassaemia Major (BTM), (c) $\mathrm{HbE}$ Heterozygous (AE), (d) HbE Homozygous (EE) 

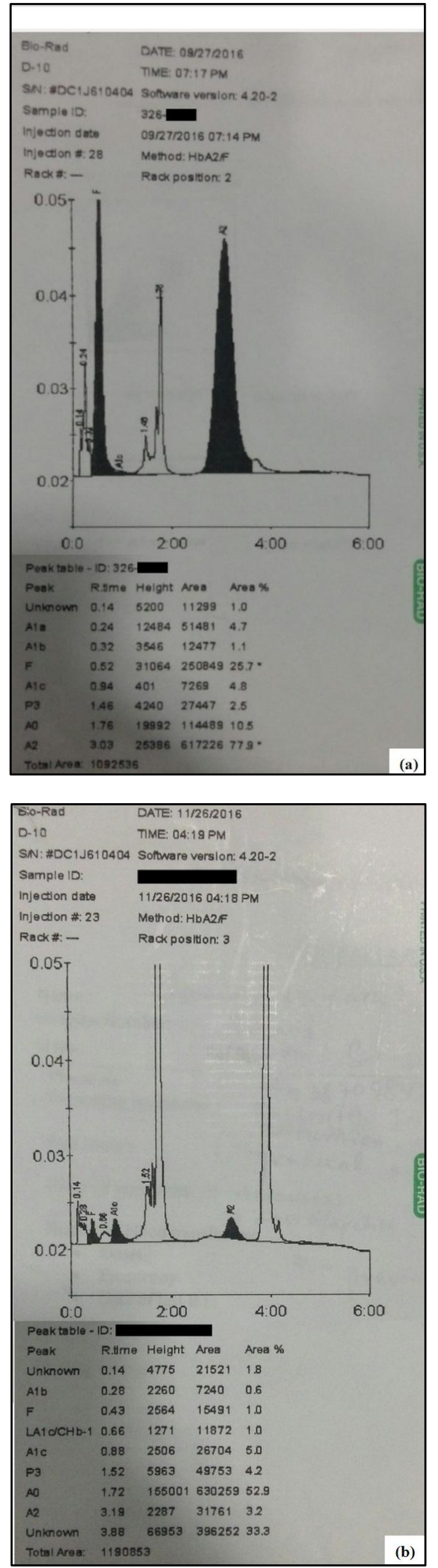
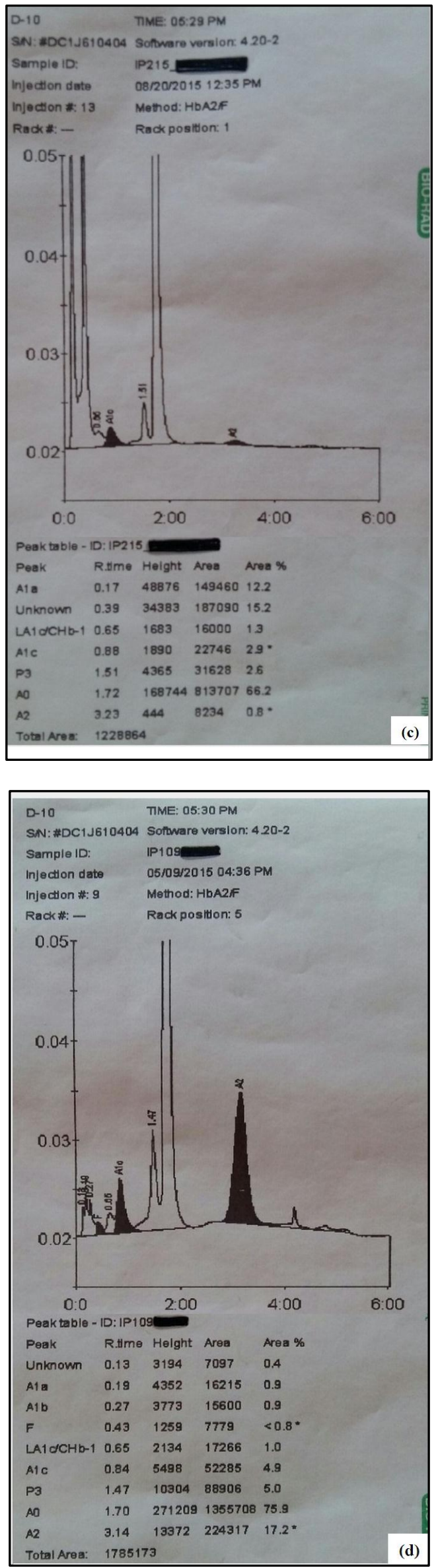

Figure 3. Chromatogram of (a) Compound Heterozygous for HbE and $\beta$-thalassaemia (Eß), (b) HbD Punjab Heterozygous, (c) HbH Disease, (d) Hb Lepore Trait 


\section{DISCUSSION}

In the present study, the prevalence of $\mathrm{Hb}$ disorders was found to be $37.26 \%$. Previous institutional based studies from Odisha reported higher prevalence (44.2\% and $65.7 \%)$ of $\mathrm{Hb}$ disorder.[4,12] However, there is a wide range of prevalence of $\mathrm{Hb}$ disorder in different parts of India. Madan et al reported a prevalence of $11.43 \%$ in a study from West Bengal.[2] Two hospital based studies from Western India got $8.6 \%$ and $11.36 \%$ of abnormal haemoglobin variants.[7,13] In the North Indian population, incidence of haemoglobinopathies was found to be $12.5 \% .{ }^{[14]}$ Baruah et al noted a high prevalence (59.11\%) in Nort-East region.[1]

$\mathrm{HbS}$ was detected in $28.17 \%$ patients, which was lower than reported by Balgir et al $(39.3 \%)^{[4]}$ but was similar to that got by Dash et al (29.0\%) ${ }^{[12]}$ from Odisha. Most common abnormal $\mathrm{Hb}$ pattern detected in this study was AS (15.10\%) followed by SS (9.90\%) and BTT (6.10\%). The two above said studies from Odisha also got AS as the most common variant followed by BTT and SS.[4,12] However, most of the other studies across the country reported BTT as the most common variant.[2,7,8,13,14,15,16] In spite of these variations, the high incidence of both AS and BTT highlights the need for antenatal screening for prevention of more severe form like BTM, SS and S $\beta$ in offspring.

The microcytic hypochromic blood picture in AS group could be due to associated iron deficiency. High incidence of iron deficiency has been reported in patients with sickle cell disease from India.[5,17] The finding of a raised $\mathrm{HbF}$ in some SCT patients was difficult to explain.

Many sickle cell homozygous patients had $\mathrm{HbF}>25 \%$. In Indian subcontinent $\mathrm{HbSS}$ patients have slightly higher $\mathrm{HbF}$ level, than the other parts of the world. The reason for this is that the haplotype of $\mathrm{HbS}$ gene, which is prevalent in India, is the Saudi Arabia/Indian haplotype, that reduces the clinical severity of the disease. ${ }^{[7,18]}$

BTT was the $3^{\text {rd }}$ most common abnormal haemoglobin variant we got. Most of the cases had characteristic microcytic hypochromic red cells with normal or slightly reduced $\mathrm{Hb}$ and raised $\mathrm{RBC}$ count. Raised $\mathrm{A}_{2}$ level is the most important abnormal chromatogram finding helpful for its diagnosis. However, conditions with borderline $\mathrm{HbA}_{2}$ need careful interpretation. Nutritional anaemia must always be taken into account. A low level of $\mathrm{HbA}_{2}$ may be induced by iron deficiency. Similarly, cobalamine or folate deficiency may raise $\mathrm{HbA}_{2}$ level. However, in previous studies no significant difference was found in $\mathrm{HbA}_{2}$ level in patients of BTT with or without concomitant iron deficiency. Thus elevation in $\mathrm{HbA}_{2}$ level can be used with reliability for diagnosis of BTT even in the presence of iron deficiency.[10,19] In our study, the peripheral red cell morphology was of help in cases of borderline elevation of $\mathrm{HbA}_{2}$. In cases of cobalamine and folate deficiency HPLC was repeated after nutritional supplement whenever feasible. Cases with normal $A_{2}$ level on repeat HPLC were taken as normal and cases still having raised $\mathrm{A}_{2}$ were diagnosed as BTT. Similarly, milder forms of thalassaemia or a co-inheritance of delta thalassaemia may also lead to borderline $A_{2}$ levels. Genetic studies should be advised in cases of dilemma for a conclusive opinion.[14]

BTM was seen in only $0.89 \%$ of patients. This low incidence of the disease may be due to decrease incidence of the disease due to effective prenatal diagnosis.
Two patients had received blood transfusion more than 1 month before diagnosis. Thalassaemia intermedia is suspected when a patient presents after 3 years of age or needs fewer blood transfusion.[17] One of our patients presented like major at the age of 7 years and diagnosed as BTI.

$\mathrm{HbE}$ is the most frequent variant $\mathrm{Hb}$ in Asia, with a significant prevalence in North-East India and Bangladesh. It is a $\beta$-chain variant that tends to elute in $A_{2}$ window on HPLC. In our study, the prevalence of $\mathrm{HbE}$ gene was $1.63 \%$ which is slightly lower than the finding observed by Balgir et al $(1.90 \%)$ in a study from Odisha.[4] HbE homozygous usually presents with $\mathrm{HbE}$ values $>70-75 \%$ and heterozygous with $\mathrm{HbE}$ values $<40 \%$. Clinical effects are more severe when $\mathrm{HbE}$ is coinherited with $\beta$-thalassaemia (E $\beta$ ).[7,14] All $\mathrm{E} \beta$ cases in our study had severe anaemia $(\mathrm{Hb} \leq 6.13 \mathrm{~g} \%)$.

Though cases of HPFH heterozygous cases have been reported, we could not find much literature about SF. We diagnosed two cases of adult onset mild anaemia as SF based on raised $\mathrm{HbF}$ and $\mathrm{HbS}$ with normal $\mathrm{HbA}_{2}$. The age of presentation and degree of anaemia helped to exclude SS. Parenteral study confirmed the diagnosis in one. Molecular study was advised in the other case for confirmation. The prevalence of SE in our study was $0.12 \%$ as compared to $0.004 \%$ in a study of more than 90,000 cases from West Bengal.[2]

Other variants detected in the present study included one case each of $\mathrm{HbD}$-Punjab trait, $\mathrm{Hb}$ Lepore and $\mathrm{HbH}$.

The gene frequency of HbD Punjab is relatively low with highest prevalence in North-Western India. Balgir et al[4] got only two cases $(0.2 \%)$ of $\mathrm{HbD}$ Punjab trait in a series of more than 1000 cases. We also got only one case $(0.12 \%)$ indicating a very low prevalence of $\mathrm{HbD}$ in Odisha. On CEHPLC, it gets eluted in the D-window, which is separate from HbS peak. Homozygous HbD disease usually presents with mild haemolytic anaemia and mild to moderate splenomegaly. Heterozygous $\mathrm{HbD}$ is a clinically silent condition, unless coinherited with HbS.[20] HPLC is useful to distinguish between HbD-Iran and HbD-Punjab. HbD-Iran gets eluted in $\mathrm{A}_{2}$ window and HbD-Punjab in the $\mathrm{D}$ window. Both the situations are clinically important because HbDPunjab produces a significant sickling disorder when coinherited with $\mathrm{HbS}$ but with HbD-Iran, the combination is clinically benign. ${ }^{77,8,21]}$

Like $\mathrm{HbD}$-Iran $\mathrm{Hb}$ Lepore also elutes in $\mathrm{A}_{2}$ window. However, the $\mathrm{HbA}_{2} \%$ in HbD-Iran (40-50\%) is significantly more than that of $\mathrm{Hb}$ Lepore (10-18\%).[11] A sharp peak in the first minute of elution indicates $\mathrm{HbH}$. $\mathrm{HbH}$ disease shows considerable variability in clinical and haematological severity.[22]

Due to socio-cultural practices, marriages in India are usually among individuals of the same caste or ethnic group and this makes it important to know the prevalence of different abnormal $\mathrm{Hb}$ variants in different ethnic groups. [23] In our country premarital screening is still considered taboo. So the best approach would be to target those patients attending the haematology OPD, the antenatal population and extended family members. The couple at risk should be counselled regarding the nature of the disease and the implications of being carriers. $[13,16]$ 


\section{CONCLUSION}

In India, where $\beta$-thalassaemia trait is so rampant, premarital and antenatal screening should be mandatory to prevent birth of children with $\beta$-thalassaemia major. Moreover, in Odisha where $\mathrm{HbS}$ is so common, the occurrence of sickle cell homozygous and compound heterozygous like $\mathrm{S} \beta$ or SE can be prevented by these screening protocols. HPLC is an excellent and powerful diagnostic tool for direct identification of $\mathrm{Hb}$ variants. The simplicity and rapidity of sample preparation, accurate quantification of $\mathrm{Hb}$ concentration combined with complete automation, makes HPLC an ideal methodology for the routine diagnosis of $\mathrm{Hb}$ disorders. $\mathrm{Hb}$ variants that are eluted in the same window can be differentiated according to the retention time and the percentage of different haemoglobins obtained. However, the chromatograms must be interpreted only in the light of other relevant investigations, family studies and if necessary molecular studies.

\section{Acknowledgement}

Authors would like to acknowledge all the staff members of Haematology section of KIMS, KIIT University for their cooperation and support during the study.

\section{REFERENCES}

[1] Baruah MK, Saikia M, Baruah A. Pattern of haemoglobinopathies and thalassaemias in upper Assam of north eastern India: high performance liquid chromatography studies in 9000 patients. Indian J Pathol Microbiol 2014;57(2):236-43.

[2] Mondal SK, Dasgupta S, Mondal S, et al. Spectrum of thalassaemias and haemoglobinopathies in West Bengal: a study of 90,210 cases by cation exchange high-performance liquid chromatography method over a period of 8 years. Journal of Applied Hematology 2014;5(3):91-5.

[3] WHO-Executive Board EB118/5, 118th Session Report by the Secretariat on thalassaemia and other haemoglobinopathies: Prevalence of haemoglobinopathies. 11 May 2006:1-8."

[4] Balgir RS. Spectrum of haemoglobinopathies in the state of Orissa, India: a ten years cohort study. J Assoc Physicians India 2005;53:1021-6.

[5] Balgir RS. The burden of haemoglobinopathies in India and the challenges ahead. Curr Sci 2000;79(11):153647.

[6] Balgir RS. The genetic burden of haemoglobinopathies with special reference to community health in India and the challenges ahead. Indian J Hemat Blood Transfus 2002;20(1):2-7.

[7] Biswas AK, Philip J. Incidence of haemoglobinopathies and haemoglobin variants using HPLC as a diagnostic tool in 6500 anemic patients in a tertiary care center in western India. IJAR 2016;6(3):214-8.

[8] Gupta PK, Kumar H, Kumar S, et al. Cation exchange high performance liquid chromatography for diagnosis of haemoglobinopathies. Med J Armed Forces India 2009;65(1):33-7.
[9] Tyagi S, Saxena R, Choudhry VP. HPLC--how necessary is it for haemoglobinopathy diagnosis in India? Indian J Pathol Microbiol 2003;46(3):390-3.

[10] Rao S, Kar R, Gupta SK, et al. Spectrum of haemoglobinopathies diagnosed by cation exchangeHPLC \& modulating effects of nutritional deficiency anaemias from north India. Ind J Med Res 2010;132(11):513-9.

[11] Joutovsky A, Hadzi-Nesic J, Nardi MA. HPLC retention time as a diagnostic tool for haemoglobin variants and haemoglobinopathies: a study of 60000 samples in a clinical diagnostic laboratory. Clin Chem 2004;50(10):1736-47.

[12] Dash NR, Mohanty B. Spectrum of haemoglobinopathies at a tertiary care hospital in Bhubaneswar, Orissa, India. J of Evidence Based Med \& Hlthcare 2015;2(34):5101-6.

[13] Bhalodia JN, Oza HV, Modi PJ, et al. Study of haemoglobinopathies in patients of anemia using high performance liquid chromatography (HPLC) in Western India. Natl J Community Med 2015;6(1):35-40.

[14] Sachdev R, Dam AR, Tyagi G. Detection of Hb variants and haemoglobinopathies in Indian population using HPLC: report of 2600 cases. Indian J Pathol Microbiol 2010;53(1):57-62.

[15] Chaudhury SR, Roy H, Bhattacharyya NK, et al. Spectrum of haemoglobin variants in eastern Indian population; a study of 14,145 cases. Al Ameen J Med Sci 2013;6(3):243-8.

[16] Singh J, Saxena M, Ahmad F, et al. Spectrum of haemoglobinopathies and thalassaemias diagnosed on hplc in a tertiary teaching hospital of northern India. National Journal of Laboratory Medicine 2016;5(3):705.

[17] Patel J, Patel A, Patel J, et al. Prevalence of haemoglobinopathies in Gujarat, India: a cross-sectional study. The Internet Journal of Hematology 2008;5(1):16.

[18] Agarwal MB. The burden of haemoglobinopathies in India: time to wake up? J Assoc Physicians India 2005;53:1017-8.

[19] Madan N, Sikka M, Sharma S, et al. Haematological parameters and $\mathrm{HbA} 2$ levels in beta-thalassaemia trait with coincident iron deficiency. Indian J Pathol Microbiol 1998;41(3):309-13.

[20] Pandey S, Mishra RM, Pandey S, et al. Molecular characterization of haemoglobin D Punjab traits and clinical-hematological profile of the patients. Sao Paulo Med J 2012;130(4):248-51.

[21] Zakerinia M, Ayatollahi $M$, Rastegar $M$, et al. Haemoglobin D (Hb D Punjab/ Los Angeles and Hb D Iran) and Co-inheritance with alpha- and betathalassaemia in southern Iran. Iran Red Crescent Med J 2011;13(7):493-8.

[22] Wadhwa R, Singh T. Role of HPLC in the detection of HbH disease. Indian J Pathol Microbiol 2011;54(2):407.

[23] Mandal PK, Maji SK, Dolai TK. Present scenario of haemoglobinopathies in west Bengal, India: an analysis of a large population. International Journal of Medicine and Public Health 2014;4(4):496-9. 